\title{
Assessment of Alveolar Bone Status of Periodontally Involved Teeth After Socket Augmentation Using Xenograft and Platelet Rich Fibrin: A Randomized Controlled Clinical Trial
}

\author{
Nesma Ahmed ${ }^{(1)}$, Mai S. Attia ${ }^{(2)}$, Eatemad A. Shoreibah ${ }^{(3)}$
}

Codex : 67/1810

azhardentj@azhar.edu.eg

http://adjg.journals.ekb.eg

\section{KEYWORDS}

Xenograft, platelet rich fibrin,

periodontally involved teeth.

\begin{abstract}
Purpose: The aim of this randomized controlled clinical trial was to radiographically evaluate hard tissue changes (bone height, width and density) in periodontally involved teeth after socket augmentation using xenograft with platelet rich fibrin compared to xenograft alone and the natural spontaneous healing. Subjects and Methods: A total of thirty extraction sockets in 18 patients were randomly divided into three groups; group I, treated by combined regenerative periodontal therapy (bone grafting using xenograft combined with platelet rich fibrin membrane). group II, treated by bone grafting using xenograft alone and group III, left untreated without bone graft or membrane placement (Control group). Radiographic parameters including linear and densometric radiographic measurements were measured at baseline then 6 months post-operatively in all studied groups. Results: Radiographic results showed statistically significant differences post operatively in all the groups. As group I (xenograft with PRF) showed statistically significant higher mean bone density, width and height post-operatively than the two other groups. Conclusion: Extraction Sockets treated with PRF combined with xenograft showed least reduction in alveolar ridge width and height and greatest increase in bone density than the other studied groups.
\end{abstract}

\section{Introduction}

Inflammatory periodontal disease is a consequence of the interaction of environmental, genetic, host and microbial factors. Destruction of tooth supporting tissues in susceptible subjects results from the shifting balance of preventive and destructive immune mechanisms against microbial pathogens. ${ }^{(1)}$ Periodontitis has been classified into chronic

- $\quad$ Paper extracted from MD thesis entitled "Assessment of alveolar bone status of periodontally involved teeth after socket augmentation using xenograft and platelet rich fibrin: A randomized controlled clinical trial"

1. Postgraduate student "Master degree" faculty of Dental Medicine, Al-Azhar University.

2. Assiociate professor of Oral Medicine, Periodontology, Oral Diagnosis, and Radiology Department Faculty of Dental Medicine, for girls, Al-Azhar University.

3. Professor of Oral Medicine, Periodontology, oral diagnosis and Radiology. Faculty of Dental Medicine, for girls, Al-Azhar University. 
and aggressive subtypes. Aggressive periodontitis is characterized by rapid progression and destruction of periodontal tissue. ${ }^{(2)}$

Although to date the goal of predictable regeneration has not been attained, but there were evidences to suggest that current regenerative techniques which include the application of root conditioners, bone grafts, guided tissue regenerative membrane, growth factors and stem cell therapy, lead to significant degrees of regeneration ${ }^{(3)}$. Growth factors are a class of polypeptide hormones known to promote proliferation and migration of periodontal ligament cells, synthesis of extracellular matrix as well as differentiation of cementoblasts and osteoblasts. They present as potential aids, in attempts to regenerate the periodontium ${ }^{(4)}$.

Xenografts are grafts shared between different species. Currently, there are two available sources of xenografts used as bone replacement grafts in periodontics: bovine bone and natural coral. Both sources, through different processing techniques, provide products which are biocompatible and structurally similar to human bone. Porcine bone xenografts have also been described. Xenografts are osteoconductive, readily available and risk free of disease transmission ${ }^{(5)}$.

Platelet-rich fibrin (PRF) is an immune and platelet concentrate collecting on a single fibrin membrane all the constituents of a blood sample favorable to healing and immunity. Though platelet and leukocyte cytokines play an important part in the biology of this biomaterial, the fibrin matrix supporting them certainly constitutes the determining element responsible for the real therapeutic potential of $\mathrm{PRF}^{(6)}$. Potential clinical indications of PRF in oral and maxillofacial surgery are numerous, including, for example, the improvement of soft tissue healing and bone graft production and remodeling. It is also useful for membrane protection or as a sole osteoconductive filling material. The combination of leukocyte and platelet rich fibrin (L-PRF) with allograft during sinus-lift and lateral grafting of the alveolar ridges also promoted more secure, quick and high quality bone regeneration ${ }^{(6)}$.

Ridge preservation with an intrasocket osseous graft and a membrane should preserve original ridge dimensions and contours, thereby facilitating optimum implant location ${ }^{(7)}$. The ridge preservation procedure has been tested in various studies ${ }^{(8,9)}$ with membrane alone or membrane plus graft, showing reduced ridge alteration compared to extraction alone. Different approaches have been recommended to reduce ridge alterations in post extraction sockets including the use of various biomaterials. Deproteinized bovine bone mineral has been successfully used in several studies to preserve ridge dimensions following tooth extraction, xenogenic bone substitute has been proven to be biocompatible and osteoconductive ${ }^{(9,10)}$.

Thus, the aim of this randomized controlled clinical trial was to radiographically evaluate hard tissue changes (bone height, width and density) in periodontally involved teeth after socket augmentation using xenograft with platelet rich fibrin compared to xenograft alone and the natural spontaneous healing.

\section{SUBJECTS AND METHODS}

This study were conducted on 30 periodontally hopeless teeth present in 18 patients include 10 females and 8 males with age range between 19 and 40 years old. Each patient possessed at least one hopeless tooth with grade III mobility diagnosed with advanced chronic periodontitis. Before the study all patients received a standard education, motivation, proper oral hygiene instructions. The patients were randomly assigned to three groups. Group (I): Included ten extraction Sockets treated by combined regenerative periodontal therapy (bone grafting using xenograft combined with platelet rich fibrin membrane).Group (II): Included 
ten extraction Sockets treated by bone grafting using xenograft alone.Group (III): Included ten extraction Sockets left untreated without bone graft or membrane placement (Control group).

\section{Preparation of platelet-rich fibrin:}

Blood samples were taken from the patient's forearm without anticoagulant in 10-ml tube and immediately centrifuged at $3000 \mathrm{rpm}$ (approximately $400 \mathrm{~g}$ according to Chokroun's calculations) for 10 minutes $^{(11)}$. Within a few minutes, the absence of anticoagulant allows activation of the majority of platelets contained in the sample to trigger a coagulation cascade. A fibrin clot is then obtained in the middle of the tube, just between the red corpuscles at the bottom and acellular plasma at the top. Platelets are theoretically trapped massively in the fibrin meshes. The exudate collected at the bottom of the box may be used to hydrate graft materials, rinse the surgical site and stored as autologous grafts ${ }^{(12)}$. After removing the cover the PRF membranes were obtained from the PRF clots. With a specific tweezer the membrane was inserted in the socket. In the current study we used glass tubes and the PRF membrane is prepared immediately before its application inside the socket.

Radiographic examination: Cone beam computed tomography was done at baseline and at six months post-operative to evaluate the alveolar bone height, width and density.

The linear measurements of Bone height was done using the 3-plane of the viewer, the axial plane was fixed on the edge of the alveolar bone of the suggested tooth site, the coronal plane fixed in the middle of the suggested tooth site, and the sagittal plane was adjusted to a location approximately midway to the total width of the tooth. This provided a general look at the tooth from the 3 different planes. A sectioning tool in the software was used to outline the entire border of the alveolar bone from the axil view which formulates an orthopantogram (OPG) view in where tomographic coronal and sagittal sections can be viewed. All height recordings were done in Orthopantogram (OPG) view using the measuring tool in the software expressed in mms. Two different recordings were measured for every tooth.

Measurements were taken from around $1 \mathrm{~mm}$ in a parallel manner away from the tooth root (mesial and distal to it). The two imaginary lines were drawn bisecting adjacent alveolar process of the selected tooth from the alveolar bone crest to the nearby anatomical landmark (inferior border of the mandible /floor of the maxillary sinus). Preoperative measurements were taken first then the height was measured at the same location post-operatively to insure standardization. Also. All width recordings were done in cross sectional view using the measuring tool in the software expressed in mms. Three different recordings were measured for every tooth (Fig 1). Three imaginary lines were drawn at 2, 4 and 6 millimeters from the alveolar bone crest extended from buccal to lingual plate of bone.

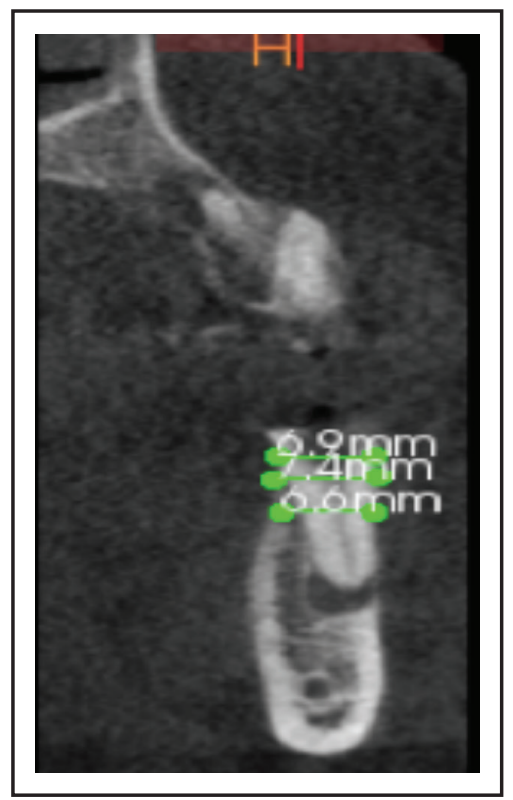

Fig. (1): Preoperative Cross sectional veiw showing bone width measurment. Three records were taken at 2,4,6 mms along the line drawn from the crest to the apex of the root. 
Furthermore, Regarding bone density measurement there was 2 measurements at 3 locations for every tooth, adding up to 6 readings per tooth. Postoperative tomographs were then analysed in the same way after calculating the location of the socket using the measurement tool. All pre and post-operative locations were re-measured by the same examiner and the average of the two measurements were considered. The mean greyscale values from each 3 points along the same line were calculated and the mean bone density measurements were recorded (the mesial and distal mean bone densities) and then analyzed. A comparison between baseline and postoperative bone density was calculated.

\section{RESULTS}

Regarding Bone density measurement after six month, there was a statistically significant difference between the three groups. Group I (xenograft with PRF membrane) showed statistically significantly higher mean bone density than the other two groups. As group I showed mean bone density was $670.61 \pm 281.01 \mathrm{HU}$. group II showed mean bone density $440.64 \pm 223.94 \mathrm{HU}$.Group III showed mean bone density $388.63 \pm 134.43 \mathrm{HU}$ after 6 months (table 1).
Regarding Bone height measurement: Group I (xenograft with PRF membrane) showed $2.51 \%$ increase in mean bone height. Group II (xenograft only) showed $1.44 \%$ increase in mean bone height. Group III (extraction only) showed $11.46 \%$ decrease in mean bone height (table 2)

Moreover, Regarding Bone width changes at $2 \mathrm{~mm}$ from crest: Group I(xenograft with PRF membrane) showed $11.83 \%$ decrease in mean bone width. Group II (xenograft only) showed $20.73 \%$ decrease in mean bone width. Group III (extraction only) showed $36.08 \%$ decrease in mean bone width. At $4 \mathrm{~mm}$ from crest: Group I (xenograft with PRF membrane) showed $6.29 \%$ decrease in mean bone width. Group II (xenograft only) showed $13.65 \%$ decrease in mean bone width. Group III (extraction only) showed $28.88 \%$ decrease in mean bone width. At $6 \mathrm{~mm}$ from crest: Group I(xenograft with PRF membrane) showed $5.41 \%$ decrease in mean bone width. Group II(xenograft only) showed $11.21 \%$ decrease in mean bone width. Group III (extraction only) showed $21.45 \%$ decrease in mean bone width (table 2)

Table (1): Results of the three groups used showing the mean bone density measurement variability throughout the study period.

\begin{tabular}{|c|c|c|c|c|c|}
\hline \multirow{2}{*}{ Bone density } & $\begin{array}{c}\text { Group I (xenograft with } \\
\text { PRF membrane) }\end{array}$ & GroupII (xenograft only) & Group III(extraction only) & F & p \\
\cline { 2 - 5 } & Mean \pm SD & Mean \pm SD & $310.08 \pm 284.51$ & 2.710 & 0.099 \\
\hline Baseline & $333.41 \pm 276.98$ & $327.72 \pm 92.18$ & $388.63 \pm 134.43$ & $\mathbf{4 . 4 1 1}^{*}$ & $\mathbf{0 . 0 3 1}^{*}$ \\
\hline 6 months & $670.61 \pm 281.01$ & $440.64 \pm 223.94$ & 0.070 & & \\
\hline P- value & 0.113 & 0.328 & & \\
\hline
\end{tabular}

$F, p ; F$ and $p$ values for ANOVA test, *: Statistically significant at $p \leq 0.05$

Mean; Mean difference., S.D.; Standard deviation of percent change 
Table (2): Results of the three groups used showing the Percentage of bone height \& width change throughout the study period.

\begin{tabular}{|c|c|c|c|c|c|c|}
\hline \multirow{2}{*}{$\begin{array}{c}\% \text { of change } \\
\text { (preoperative - } \\
\text { post-operative) }\end{array}$} & \multicolumn{2}{|c|}{$\begin{array}{l}\text { Group I (xenograft with } \\
\text { PRF membrane) }\end{array}$} & \multicolumn{2}{|c|}{$\begin{array}{c}\text { Group II } \\
\text { (xenograft only) }\end{array}$} & \multicolumn{2}{|c|}{ Group III (extraction only) } \\
\hline & Mean & \pm SD & Mean & \pm SD & Mean & \pm SD \\
\hline Bone height & $\uparrow 2.51$ & 3.27 & $\uparrow 1.44$ & 1.83 & $\downarrow 11.46$ & 3.26 \\
\hline \multicolumn{7}{|l|}{ Bone width } \\
\hline $2 \mathrm{~mm}$ from crest & $\downarrow 11.83$ & 2.32 & $\downarrow 20.73$ & 6.25 & $\downarrow 36.08$ & 9.48 \\
\hline $4 \mathrm{~mm}$ from crest & $\downarrow 6.29$ & 3.15 & $\downarrow 13.65$ & 7.44 & $\downarrow \mathbf{2 8 . 8 8}$ & 12.60 \\
\hline $6 \mathrm{~mm}$ from crest & $\downarrow 5.41$ & 2.92 & $\downarrow 11.21$ & 8.67 & $\downarrow 21.45$ & 12.0 \\
\hline
\end{tabular}

Mean; Mean difference.

S.D.; Standard deviation of percent change.

\section{DISCUSSION}

Previously, several authors have reported the use of combined regenerative therapy in the socket preservation. This preservation in the periodontally involved teeth had not been discussed. Therefore, to our knowledge, it appears that the current study may be the first study to evaluate the assessment of alveolar bone status of periodontally involved teeth after socket augmentation using combined regenerative therapy. Thus, the present study was conducted to evaluate bone formation in extracted sockets of periodontally hopeless teeth utilizing platelet rich fibrin combined with xenograft or xenograft alone. These modalities had been utilized to assure the long-term stability of the bone volume to minimize the loss of bone height and buccolingual width following tooth extraction based on solid documentation in the literature ${ }^{(13-16)}$.

The grafting materials used for augmentation after tooth extraction are able of providing a mechanical support and prevent the collapse of both the buccal and lingual bone walls, thus delaying residual ridge resorption and remaining in the place until enough healing (new bone formation) occurs ${ }^{(17)}$. In the present study, bovine xenograft was used to achieve high quality and quantity of bone after extraction. They contain similar hydroxyapatite content to that of human bone, which allows the graft to be osteoconductive to revascularize and be replaced by new human bone. Xenografts originally were safety used in periodontal therapy and generally resulted in enhancement of wound healing when compared to ungrafted sites ${ }^{(18,19)}$. Bovine bone is associated with a $20 \%-40 \%$ retention of the graft after six months, as well as after three years, following placement. Thus, This slow substitution rate allows long-term space maintenance ${ }^{(20)}$. Moreover, many studies have found that inorganic bovine bone shows better bone formation potential than other HA materials ${ }^{(21-23)}$.

On the other hand, the addition of PRF to xenograft convert them from osteoconductive into osteoinductive materials by stimulating undifferentiated mesenchymal cells to be differentiated into osteoblasts that form new bone. ${ }^{(24)}$

In the present study, focusing on 30 extractions sites, that; there was no statistically significant difference in bone height in all studied groups pre- operatively. While post-operative; group I (xenograft with PRF membrane) showed statistically significantly higher mean bone height than the other two studied groups.

In the present study the results were in accordance with another study ${ }^{(25)}$ who compared the hydroxyapatite bone graft and extraction alone for the preservation of extraction socket in which 
hydroxyapatite plug was used in single rooted teeth in maxillary canine and he concluded that hydroxyapatite bone graft helps in preservation of the height and width of the socket and ultimately preserves the ridge which helps in less resorption of the socket and ridge which ultimately helps in better future prosthesis for the patient.

In the present study, it was observed that there was no statistically significant difference in bone width in all studied groups at 2, 4 and $6 \mathrm{~mm}$ from the alveolar crest pre-operatively. However, group I (xenograft with PRF membrane) showed statistically significantly higher mean bone width than the other two studied groups post-operatively.

In a previous study ${ }^{(26)}$, evaluated the use of xenograft and PRF in treating full or partial buccal bone defects of fresh extraction sockets in the esthetic zone was evaluated. Findings from their study showed that xenograft and PRF, used for ridge preservation of the extraction sockets in the esthetic zone, can be considered effective in repairing bone defects before implant placement. Moreover, their results are in agreement with the results of the current study.

In the current study, group I (xenograft with PRF membrane) showed statistically significantly higher mean bone density than the other two groups after six months. This could be attributed to different biological and mechanical properties provided by grafting materials that optimized the environment for the regeneration of vital bone ${ }^{(27)}$.

In conclusion, Immediate socket augmentation might provide advantages in the management of extraction sockets in periodontally compromised teeth. Superior results obtained by the use of PRF combined with xenograft compared to the other studied groups and this was confirmed radiographically. The extraction Sockets treated with PRF combined with xenograft showed least reduction in alveolar ridge width and height and the greatest increase in bone density than the other studied groups.

\section{REFERENCES}

1. Kinane DF, Stathopoulou PG, Papapanou PN. Periodontal diseases. Nat Rev Dis Primers. 2017 Jun 22;3:17-38.

2. Armitage, G.C. Development of a classification system for periodontal diseases and conditions. Ann Periodontol 1999; 4:1-6.

3. Polimeni G, Xiropaidis A, V, Wikesjo U, M, E. Biology and principles of periodontal wound healing/regeneration, Periodontol 2000, 2006; 41: 30-47.

4. Lovelace T. B, Mellonig J, T, Meffert R, M., Jones A. A, Nummikoski P, V, Cochran D, L. Clinical evaluation of bioactive glass in the treatment of periodontal osseous defects in humans, J Periodontol, 1998; 69:27-35.

5. Sheikh Z, Hamdan N, Ikeda Y, Grynpas M, Ganss B, Glogauer M. Natural graft tissues and synthetic biomaterials for periodontal and alveolar bone reconstructive applications: a review. Biomater Res. 2017 Jun 5; 21:9.

6. Simonpieri A, Del Corso M, Vervelle A, Jimbo R, Inchingolo F, Sammartino G and Dohan Ehrenfest DM. Current Knowledge and perspectives for the use of Platelet Rich Plasma (PRP) and Platelet Rich fibrin (PRF) in oral and maxillofacial surgery part 2:Bone Graft, implant and reconstructive surgery. Curr Pharm Biotechnol. 2012; 13: 1231-56.

7. Poulias E, Greenwell H, Hill M, Morton D, Vidal R, Shumway B, Peterson TL. Ridge preservation comparing socket allograft alone to socket allograft plus facial overlay xenograft: a clinical and histologic study in humans. J Periodontol. 2013 Nov; 84:1567-75.

8. Molly, L., Vandromme, H., Quirynen, M., Schepers, E., Adams, J.L. \& van Steenberghe, D. Bone formation following implantation of bone biomaterials into extraction sites. Journal of Periodontology 2008; 79: 1108-15.

9. Gholami GA, Najafi B, Mashhadiabbas F, Goetz W, Najafi S. Clinical, histologic and histomorphometric evaluation of socket preservation using a synthetic nanocrystalline hydroxyapatite in comparison with a bovine xenograft: a randomized clinical trial. Clin. Oral Impl. Res. 2012; 23: 1198-04.

10. Carmagnola, D., Berglundh, T., Arau’ jo, M., Alberktsson, T. \& Lindhe, J. Bone healing around implants placed in a jaw defect augmented with Bio-Oss. An experimental study in dogs. Journal of Clinical Periodontology 2000; 27: 799-805.

11. Dohan Ehrenfest, D.M.; del Corso, M.; Diss, A., Mouhyi, J., Charrier, J.B. Three-dimensional architecture and cell composition of a Choukroun's platelet-rich fibrin clot and membrane. J. Periodontol. 2010;81:546-55. 
12. Fernandes G, Yang S. Application of platelet-rich plasma with stem cells in bone and periodontal tissue engineering. Bone Res. 2016 Dec 13;4:16036.

13. Yang Z., "Osteogenesis in extraskeletally implanted porous calcium phosphate ceramics: variability among different kinds of animals". Biomaterials,1996;17: 2131-37.

14. Morjaria KR, Wilson R, Palmer RM. Bone healing after tooth extraction with or without an intervention: a systematic review of randomized controlled trials. Clin Implant Dent Relat Res 2014;16:1-20.

15. MG Triveni, MA Tarunkumer, Vinita Jain, dahoom S Mehta. Alveolar ridge preservation with B_TCP and platletrich fibrin. international journal of oral implantology and clinical research , 2012;3(2):96-100.

16. Serino G, Rao W, Iezzi G, Piattelli A. Polylactide and polyglycolide sponge used in human 39. extraction sockets: bone formation following 3 months after its application. Clin Oral Impl Res 2008;19:26-31.

17. Rodella, L.F., Favero, G., Labanca, M. Biomaterials in maxillofacial surgery: Membranes and grafts. Int. J. Biomed. Sci. 2011;7:81-88.

18. AlGhamdi, A.S., Shibly, O., Ciancio, S.G. Osseous grafting part II: Xenografts and alloplasts for periodontal regeneration, A literature review. J. Int. Acad. Periodontol. 2010; 12: 39-44.

19. Fee L. Socket preservation. Br Dent J. 2017 Apr 21; 222: 579-82.

20. Berglundh T, Lindhe J. Healing around implants placed in bone defects treated with Bio-Oss. An experimental study in the dog.Clinical Oral Imp Research, 1997; 8: 117-24.

21. Piattelli M, Favero G A, Scarano A, et al. Bone reactions to anorganic bovine bone (Bio-Oss) used in sinus augmentation procedures: a histologic long-term report of 20 cases in humans. The International Journal of Oral \& Maxillofacial Implants, 1999; 14: 835-40.

22. Carmagnola D, Adriaens P, Berglundh T. Healing of human extraction sockets filled with Bio-Oss. Clinical Oral Implants Research, 2003; 14: 137-43.

23. Caubet J, Petzold C, Sáez-Torres C, et al. Sinus graft with safescraper: 5-year results. Journal of Oral and Maxillofacial Surgery, 2011; 69: 482-90.

24. Arora S, Kotwal U, Dogra M, Doda V. Growth Factor Variation in Two Types of Autologous Platelet Biomaterials: PRP Versus PRF. Indian J Hematol Blood Transfus. 2017; 33:288-92.

25. sachdev et al. a comparison in preservation of extraction socket with hydroxyapatite bone graft and extraction alone: a clinical and radiographic study" a case report, indo-European j. of den. therapy and research 2015; 4:315-18.

26. Barone A, Ricci M, Romanos GE, Tonelli P, Alfonsi F, Covani U. Buccal bone deficiency in fresh extraction sockets: a prospective single cohort study. Clin Oral Implants Res. 2015 Jul; 26:823-30.

27. Thakkar DJ, Deshpande NC, Dave DH, Narayankar SD. A comparative evaluation of extraction socket preservation with demineralized freeze-dried bone allograft alone and along with platelet-rich fibrin: A clinical and radiographic study. Contemp Clin Dent. 2016; 7:371-76. 